\title{
STUDENT EXPERIENCES OF USING WEBLOGS: AN EXPLORATORY STUDY
}

\author{
Priya Sharma \\ The Pennsylvania State University \\ Ying Xie \\ The Pennsylvania State University
}

\begin{abstract}
Recently, attempts have been made to use Weblogs and other personal webpublishing technologies to support individual and social reflection in higher education. Weblogs can be highly individual and reflective in nature, and students' experiences and perceptions of the technology and practice are of primary importance in furthering educational use. In this phenomenological study 8 participants who maintained Weblogs in a graduate course were interviewed. Initial data analysis indicates that participants found Weblogs helpful for learning, reflecting, and building a sense of community. However, participants expressed concerns over the lack of structure for Weblog usage and the public nature of the reflective process. Implications for future practical and research applications of Weblogs are presented.
\end{abstract}

\section{KEYWORDS}

Weblog, Blog, Reflection

\section{INTRODUCTION}

Personal Webpublishing systems, of which Weblogs are one popular instantiation, are increasingly used in social, political, educational, and business settings. Reports on usage of Weblogs (or blogs) and practices of writing on Weblogs (or blogging) abound in both popular and academic literature. Estimates of the number of extant Weblogs range between six and eight million in the U.S. alone [1]. The large majority of Weblogs are personal and informal - that is, the content is written by an individual and represents a personal view. Although empirical research is still scarce, Weblogs are increasingly being integrated into education, especially into higher education to support student speech and to inculcate higher order thinking [2] and also to introduce students to academic thinking and discourse [3].

In higher education, Weblogs have been implemented to learn about journalism and current events [4], and to support self-directed learning [5], analytical thinking [6], and self-organized and reflective thinking [7]. Practical evidence indicates that students engage sporadically in the writing of the Weblogs, even though most indicate an awareness of benefits of blogging [e.g. 4, 6]. In our research, we implemented Weblogs to foster student reflection and to support students in meaning-making and articulation about the process of instructional design. However, as with other studies, our investigations indicated that students found it difficult to engage consistently in reflective writing on the Weblogs. For example, some students wrote sporadically, while others focused on trivial, non-reflective aspects of the design process.

In this paper, we examine student experiences of using Weblogs for reflection; specifically, we focus on identifying experiences that aided or hindered students' practice of reflecting on the Weblogs. We 
describe data collection and analysis, and present findings that emerged from the data. We conclude by discussing these findings and identifying their implications for further research and practice.

\section{USING WEBLOGS TO ENGAGE STUDENTS IN REFLECTION}

Personal Webpublishing has emerged as a popular technology-based instantiation of journaling in the past few years. Weblogs, one of the most popular forms of personal Webpublishing, allow individuals to publish their thoughts, commentaries, and reflections in the form of individual posts of varying lengths on a Web page. Since the software is server-based, a Weblogger (or blogger) can log in from any Internetenabled computer and add new posts, thus supporting the possibility of spontaneous recording of thoughts and experiences. Weblogs offer two advantages for reflection: one, they support student ability to record and revisit experience, which is an important part of reflective learning [8], and two, Weblogs offer the potential for abstraction - by writing posts, students are perforce engaged in articulating thoughts and feelings, which can lead students to reflect on their understanding of content and own learning $[9,10,11]$.

Reflective journaling on a Weblog is different from writing on online bulletin boards or chats, even though each forum allows individual publishing of thoughts and arguments. Writing on discussion boards and chat rooms is essentially a dialogue between multiple individuals; that is, the posts are interwoven and build on each other. Conversational triggers are generated by different individuals and most often the responses are posted in reaction to specific conversational gambits. Weblogs, on the other hand, represent an individualized space that is more supportive of a dialogue with self than others. Although empirical research on Weblog use in higher education is relatively scarce, informal accounts from practitioners and researchers indicate that Weblogs can be an important individual conversational learning space [e.g., 12]. Weblogs also allow for the integration of a wider range of information from other online sources [13], and encourage individual critique, commentary, and evaluation of varied information sources since quality of writing and content is indicative of higher numbers of readers [14]. Weblogs can offer significant advantages because they support consistent, long-term individual monologues, and simultaneously allow commentary and evaluation by others [14].

\section{WEBLOG USE IN HIGHER EDUCATION}

Informal accounts of Weblog use in educational settings abound, but published research reports on this topic are infrequent. Some empirical research exists on the role of discourse and communication in Weblog communities [see for example, 15], where the focus is on naturalistic reports of Weblogging practices that emerge within the informal community. In formal education, however, empirical reports on students' use of blogs are rare. Informal reports of blogging indicate that student use of and writing on blogs is affected by multiple influences; however, no systematic effort has been made to describe the sources of influence and student reactions to these influences.

For example, Bartlett-Bragg [5] summarizes informal student discussions on the use of Weblogs: Students found Weblogs useful for freedom of commenting, for publishing unconnected pieces of knowledge that were personally meaningful, and as a space to record learning so that it could be revisited. Hernàndez-Ramos [16] used Weblogs in a teacher preparation course and based on student writing on the blogs, he identified that a majority of the students found the experience rewarding and different. He also identified that some students had passionately adopted the blogging practice, while other students were reluctant to engage in the process. However, Hernàndez-Ramos [16] did not present further evidence about why students reacted positively or negatively to Weblog usage. Williams and Jacobs [17] surveyed graduate business school students who were encouraged to use blogs over a six week period in one of their courses. Only half the students chose to blog; their opinions were collected using a Likert-scale type 
survey. Most students felt that blogs helped their learning and cited discussion and time to reflect on their blogs as key aspects in blogging. Students also felt that blogs allowed meaningful exchanges of information between peers. However, Williams and Jacob's [17] survey did not provide any specific or detailed information on what prompted students to blog or what factors supported their engagement with this medium. The points awarded to blog participants were so few that, in fact, students who did not participate in the blogging cited low points as a lack of incentive. However, additional details on why some students chose to blog despite low-value of external rewards could have provided some more information on the influences on student blogging.

The examples cited above are among the few studies that cite empirical or anecdotal data in support of student perceptions of Weblogs, however, none of them describes in detail the influences that affect student usage of Weblogs for reflection in formal settings. Since reflection combines affective and cognitive attitudes and skills, an understanding of students' experiences with and their attitudes towards this technology and practice could potentially offer guidelines for using Weblogs to enrich students' learning experiences. Thus, our focus for this study was: how do graduate students engaged in coursespecific web logging activities describe their experiences of reflecting on the Weblogs?

\section{RESEARCH CONTEXT AND METHODS}

Field research methods were employed to explore the experiences of graduate students in their Weblogging activities. A phenomenological approach was selected as the most useful research method in this context [18].

\begin{tabular}{|c|c|c|c|c|c|}
\hline Participant & Age & Study Major & $\begin{array}{l}\text { Previous } \\
\text { Blogging } \\
\text { Experience }\end{array}$ & $\begin{array}{l}\text { \# of } \\
\text { Posts }\end{array}$ & Content of Weblogs \\
\hline Scott & 40 & Adult education & No & 13 & $\begin{array}{l}\text { - comments on text } \\
\text { - comments on project content }\end{array}$ \\
\hline Jack & 34 & Adult education & Yes & 14 & $\begin{array}{l}\text { - comments on text and other } \\
\text { web-based articles } \\
\text { - reflections on designing and } \\
\text { designers } \\
\text { - reflections on project process }\end{array}$ \\
\hline Lisa & 34 & $\begin{array}{l}\text { Instructional } \\
\text { systems }\end{array}$ & No & 13 & $\begin{array}{l}\text { - comments on text and other } \\
\text { web-based articles } \\
\text { - reflections on design and } \\
\text { learning theories } \\
\text { - reflections on own learning } \\
\text { and activity }\end{array}$ \\
\hline Tom & 27 & $\begin{array}{l}\text { Instructional } \\
\text { systems }\end{array}$ & No & 14 & $\begin{array}{l}\text { - comments on text and other } \\
\text { web-based articles } \\
\text { - reflections on role of design } \\
\text { and designers } \\
\text { - comments on the process of } \\
\text { blogging }\end{array}$ \\
\hline Betty & 32 & $\begin{array}{l}\text { Curriculum and } \\
\text { Instruction }\end{array}$ & No & 7 & $\begin{array}{l}\text { - reflections on prior design } \\
\text { experiences }\end{array}$ \\
\hline
\end{tabular}




\begin{tabular}{|c|c|c|c|c|c|}
\hline & & & & & $\begin{array}{l}\text { - } \text { reflections on instructional } \\
\text { design and teaching } \\
\text { - comments and resources } \\
\text { related to the project }\end{array}$ \\
\hline Jane & 32 & $\begin{array}{l}\text { Workforce } \\
\text { education }\end{array}$ & No & 8 & $\begin{array}{l}\text { - comments on text and other } \\
\text { web-based articles } \\
\text { - reflections on design and } \\
\text { being a designer } \\
\text { - comments on project } \\
\text { progress and processes }\end{array}$ \\
\hline Eric & 30 & $\begin{array}{l}\text { Instructional } \\
\text { systems }\end{array}$ & No & 1 & $\begin{array}{l}\text { - general thoughts about } \\
\text { design }\end{array}$ \\
\hline Cathy & 24 & $\begin{array}{l}\text { Instructional } \\
\text { systems }\end{array}$ & No & 9 & $\begin{array}{l}\text { - comments on text and other } \\
\text { web-based articles } \\
\text { - reflections on design, } \\
\text { technology, and role as } \\
\text { designer }\end{array}$ \\
\hline
\end{tabular}

Table 1: Participants Demographic Information

Study participants were 8 doctoral students - four males and four females between 24 and 40 years old - who enrolled in a graduate level instructional design course offered at a large northeastern university (see Table 1 for participant profiles). The study participants maintained Weblogs for one academic semester as part of the graduate course requirement. Each student was provided an individual Weblog and the capability of posting any number of comments per day and the ability to upload pictures and files, if needed. The instructor maintained a main course Weblog providing administrative information and additional content and links as needed. The instructor also referenced posts made on individual student Weblogs on the main course log. All course weblogs (including the instructor's) were cross-indexed on each individual's Weblog page so that students could easily view others' Weblogs by clicking on the links. Although students were encouraged to comment on other student Weblogs, the instructor did not provide any direct intervention to encourage the discourse, except to reference different student Weblogs on the main course log. On average, each student posted at least one comment per week on the individual Weblog. Criterion sampling [19] was used to select class participants who had maintained Weblogs for at least one semester. In addition, the participants were willing to participate in the study and describe their experiences and thoughts in great detail [20].

\section{DATA COLLECTION AND ANALYSIS}

An interview guide [21], which combines pre-determined and spontaneously generated questions, was used to conduct an hour-long interview with each participant. Interview questions revolved around the following main themes: students' experiences and feelings about using Weblogs, their approach to reflecting on the Weblogs, and their perceptions of utility in their learning. Table 2 lists the predetermined questions used to probe student experiences of Weblog usage. These standard questions were augmented with additional open-ended questions to probe a participant's specific thoughts and responses.

\section{You kept Weblogs for a whole semester. Could you tell me what you did, what you didn't do, and how you felt?}

a. Can you talk specifically about when you wrote on the weblog and 
why?

b. What things encouraged you to write?

c. What discouraged you from writing?

d. What types of writing did you do on the Weblog?

e. How did you develop an idea of what and how to write on the Weblog?

2. How did the experience of Weblogging affect you?

a. What feelings were generated by the experience? What instances made you feel that way?

b. What thoughts stood out for you?

3. Did you develop a style while using the Weblog?

How did that style emerge?

4. How often did you visit other classmates' weblogs? Why did you visit them?

5. How often did you visit other Weblogs outside of the course? Why did you visit them?

6. How did Weblogs affect your learning in the course?

Table 2: Interview questions for probing student feelings about Weblogging

All interviews were transcribed and transcribed data were analyzed using N-Vivo. Free codes and axial codes were generated through analyses of the interview transcripts. Data analyses comprised preliminary grouping, also called "horizonalization," [20], thematic labeling, and finally, developing a textualstructural description. Table 3 presents a sample of horizonalization and thematic coding. The aim was to develop a composite description of experiences of participants and identify different influences on perceptions and on the use of Weblogs and their contribution to students' reflective thinking and learning. After the primary data analysis, individual interview summaries were sent to participants to confirm accuracy of interpretation. Additional data triangulation was achieved through peer review of codes. 


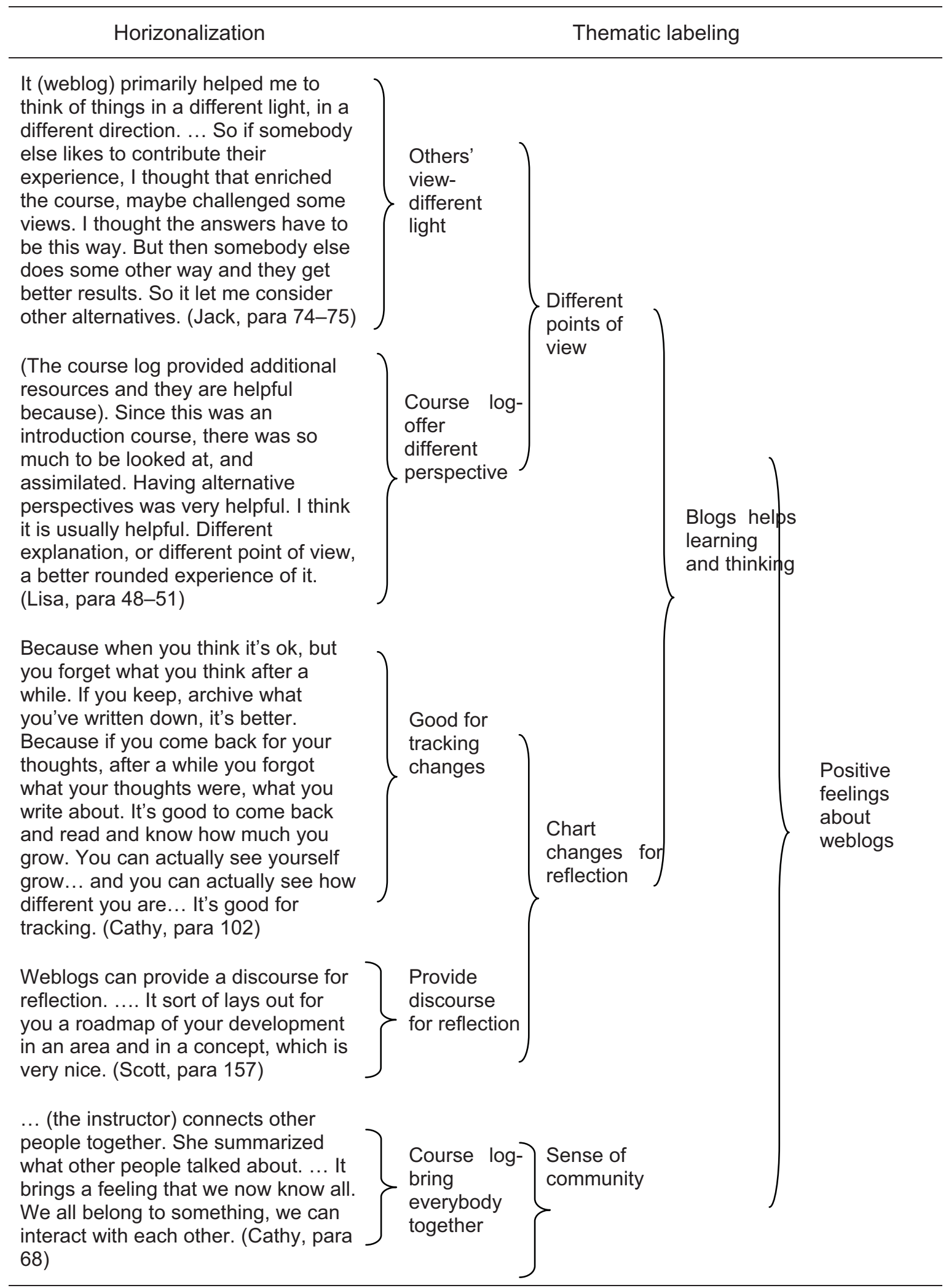

Table 3: Examples of Horizonalization and Thematic Labeling 


\section{FINDINGS AND THEMES}

Data analysis at a more categorical level is still ongoing, but here we present some of the initial themes that have emerged through analysis. Overall, student experiences can be grouped as positive and negative. Most students categorized their Weblogging experiences as being positive because they felt that Weblogging helped their learning and thinking and offered a space outside of the class where they could "meet," creating a sense of community. Also, being graduate students in instructional design, participants were motivated to explore a new type of technology and to understand and tap its potential for their own future instructional design uses. Negative experiences were related to lack of privacy and lack of structure on blogging procedures, which in turn resulted in frustration and decreased motivation to engage in the activity. Table 4 presents an overview of the themes corresponding to positive and negative experiences about Weblog usage.

\section{Positive experiences}

1. Weblogging helped thinking and learning
a. Providing access to different viewpoints
b. Providing space for organization and collection
c. Triggering careful examination of content

2. Weblogging provided a sense of community

\begin{tabular}{ll}
\hline \multicolumn{2}{c}{ Negative experiences } \\
\hline 1. Uncertainty about correct usage of Weblog \\
2. Differences in familiarity and experience with \\
content \\
3. Concerns about privacy \\
\hline
\end{tabular}

Table 4: Themes Related to Participant Perceptions of Weblogs

\section{A. Weblogging Helped Thinking and Learning}

The first theme in the positive experiences of Weblogging is related to participants' perceptions of the utility of Weblogs in aiding thinking and learning. Primarily, participants perceived that Weblogs supported their learning by providing different viewpoints, by providing a space where changes in thinking could be charted, and by requiring them to think more critically about reading materials and resources.

\section{B. Providing Access to Different Viewpoints}

Obtaining different viewpoints was identified as important in supporting participant thinking and learning. Participants suggested that the instructor's and other students' Weblogs were useful in providing diverse perspectives and information beyond the class content. The various Weblogs also provided ways of connecting course content to individual experiences. The diverse perspectives were deemed helpful in 
providing a holistic, in-depth view of the content, as is evidenced by Scott's description.

...have others to offer their thoughts and opinions ... and offer another point of view, something else from another point of view. And now you are looking at the whole spectrum, you are not looking at one part of a circle. In fact, you are looking at many arcs in hopes of completing a circle of knowledge toward a particular subject... You may find further thoughts deeper than your own thoughts through reading what others have to say, or listening to others' ideas and reflections. And that furthers what's in your mind. And it deepens, broadens your understanding of the material. And it makes your ideas applicable for some research in the future, or opens up avenues you have never thought prior to that. So it gives you ideas, spurs different thoughts in your mind and deepens your understanding.

Two participants commented on the diversity of perspectives as helpful for challenging and augmenting their thinking. Jack, for example, referred to the utility of other views in enriching and presenting alternatives to his thinking. He said that others' experiences challenged some views where he "thought the answers have to be this way." Lisa commented on the utility of other perspectives in allowing her to glimpse a holistic picture of the topic: "I think it is usually helpful to have a different explanation, or different point of view, a better rounded experience of it."

\section{Providing Space for Organization and Collection}

Participants also perceived that Weblogs helped their thinking by providing space for organizing and synthesizing thinking as part of their learning. Scott and Jack appreciated the provision of a structured space to archive different pieces of information and thus gain a composite view of this information. Scott appreciated the utility of the medium to "organize your thoughts, see how well you do understand the material." Jack similarly commented:

...as a part of my own study, I gain from so many different places. Like, I have to read a chapter, an article, and another article. They are isolated in their presentation, but the weblog kind of helps me to read them into something that makes sense. You take learning, bring it into your own context and structure it to make more sense. The process I was going through I thought was rewarding. I was able to construct these blocks into new blocks of my own when I came into the class with my own mental model of how the pieces work together, instead of just pieces.

Jane and Tom presented a slightly different perspective, commenting on the utility of Weblog writing as a mechanism to organize and articulate their thinking. Jane commented that writing was "a process that makes you think in an ordered way" and she found the space helpful in summarizing her thoughts. Tom perceived the Weblogs as space that engaged him in tracking his thoughts and "to think and articulate ideas."

Information organization and archiving on the Weblogs was also perceived by participants as being useful in "charting" changes in thinking. As participants revisited their Weblogs, they perceived changes and growth in their writing and thinking, and that helped them to reflect on their learning. Scott perceived that the Weblog allowed him to view the integration between old and new knowledge, commenting, "it sort of lays out for you a roadmap of your development in an area... you can chart your thoughts from day one to the end of semester to see how your thoughts developed." Cathy felt that the Weblog reflections allowed her to archive and track thoughts, and see "how different" she was and how she had progressed in her thinking. 
Besides allowing him to compare a progression of thoughts, Tom also perceived that Weblogs increased the pace of his thinking and change, commenting that without a concrete historical perspective, he may have found it difficult to reflect on his learning. He felt that Weblogs helped him to "articulate ....and compare ideas" by providing "a history of ...thoughts."

\section{Triggering Careful Examination of Content}

Weblog publishing also encouraged participants to focus on their reading materials. The requirement to write on Weblogs "pushed [them] into deep thinking" about the content, as indicated by Jack.

For me as a student, it was an opportunity to do something with the material aside from just reading it. So it was educational experience just writing itself... because it keeps me actively interested in what I am reading instead of sometimes when you read, you drift off, you lose your attention. But it keeps my attention... Aside from just giving me the opportunities to express them, it helps me to focus, I think. It helps me with the synthesis step, so things make a little more sense... it gets me more interested in the subject matter. I think it made me feel more confident too because I kind of thought it over, you know. I already considered the content and put it together in a new way that makes sense to me. (Jack)

Participants also identified the requirement to post as a trigger for engaging in in-depth analysis of reading materials and content. Lisa explained that writing for the Weblog made her more prone to evaluate content and said that she tended to "look more critically ... I would want to know something more where it [content] didn't fit my experiences." Cathy admitted to using a more procedural strategy for recording thoughts consistently, using the Weblog as a place to store her thoughts as she read content.

The previous three sections referred to positive experiences of blogging in helping thinking and learning. Another positive experience was related to the sense of community engendered by Weblogs. Participants felt that the sense of closeness contributed positively to the experience; however, they did not relate it directly to their learning. In the next section, we elaborate on this perception.

\section{E. Weblogging Provided a Sense of Community}

Participants perceived that Weblogs created a sense of community and extended discussion within and outside of the class. For some participants, such as Scott and Lisa, the involvement with other students contributed to a sense of togetherness, which seemed important in supporting their learning. Scott commented on the importance of shared learning experiences in stimulating mutual growth among class participants.

My feeling is that you are part of a community. That was nice. You feel you are part of a group, part of an effort. You are actually included something. You don't feel you are alone, because even though you are new to the field, you are still struggling. And it is that feeling of cooperate that we are all struggling to understand this together ... At least it opened up that avenue that I wasn't going through, trying to understand it alone... being a part of learning community helps to stimulate and sustain that growth. And being able to share with others to me is the importance of a learning community, to help stimulate my growth and help to stimulate someone else. And we can sustain ourselves over the course of, in this case, a semester, but you would hope that that information becomes part of you, part of your repertoire, such that it is the basis on which you do further decisions. (Scott) 
Cathy commented on the Weblog's utility for accessing other people's views and engendering a sense of familiarity for others. She felt that the instructor's log, by summarizing different logs, gave a "feeling that we now know all. We all belong to something, something we can interact with." She specifically admitted liking "the sharing, the community, the interaction with other people" that emerged from Weblog interactions.

Three participants commented on the ability of Weblogs to extend discussion and generate conversations. Jane and Lisa perceived the Weblog as a space to invite additional conversation. Lisa commented that reading others' Weblog reflections would trigger face-to-face conversations, either to clarify or counter a prior post. She felt that this mechanism opened "a door for additional communication face to face." Jane similarly liked the additional interaction generated by Weblogs, especially when she posted a "very interesting, very original or creative idea." This type of posting led to the initiation of conversations by interested readers, and Jane felt that this was "good."

\section{POSITIVE EXPERIENCES AND PERCEPTIONS RELATED TO WEBLOGGING}

The first positive experience of blogging was related to the availability of different perspectives on content. Reflection can be construed both as a solitary and social activity [22]. Some theorists envision reflection as an individual process but conceive of reflective practice in a social plane, where individual artifacts, thoughts, and reflections are shared and commented on in a public space [23]. The combination of individual reflection and access to the group's reflections seemed to challenge participants' thinking and interests. This type of dialogic interaction with artifacts is key to reflective and critical thinking [24, 25], which encourages careful examination of one's thinking in the context of competing (or consensual) views.

Weblogging seemed to be very important in providing space for students to organize and archive contentfocused, reflective commentaries. Individual Weblogs allowed students to record their thoughts and feelings, which were then revisited as needed. This iterative sequence of recording, followed by reflection on the feelings is central to the conception of reflection suggested by [8]. In this case, Weblogs seemed to offer a benefit similar to those offered by personal diaries - the ability to serve as a record for thoughts, which is available for re-reading [see for example, 26]. Like diaries, Weblogs also were able to support student self-expression, which as research indicates, is generally appreciated by students [27, 28]. Educators in math and science have propounded the utility of an explicit space and semiotic modality for reflection [see for example, 29], and the inclusion of specific interactions that support individual and social reflection.

Another positive perception of Weblogs was related to the utility of writing on the Weblogs and its contribution to reflection. The participants commented that they valued the ability to use writing as a method to think deeply and to articulate ideas. Sá [30], for example, suggests that writing is useful to represent thinking as well as to develop skills for thinking and articulating thoughts. Keys [31] identifies three types of writing in writing to learn - expressive, transactional, and poetic. Expressive writing is informal, personal, and without consideration for others' judgments, thus allowing the writer to make connections between prior and new knowledge. Transactional writing, on the other hand, is more communicative and focuses on writing to an audience. It appeared that students generally regarded the Weblogs as transactional rather than as an expressive writing space, as is apparent in Scott's quote: 
I was writing to myself. But in the back of my mind, I knew almost anybody can see this.... what was there [on the Weblog] had already been considered, it wasn't initial pure thoughts. It was items which I had already addressed and once they were dressed up, made more sense, they were entered at that point of time.

Data also indicate that participants perceived writing as a way to learn rather than purely as an end product of learning, much as established in Jasper's [11] research with nursing students. According to some participants, the act of writing triggered careful examination of content. In the context of writing diaries for qualitative research, Sá [30] identifies the importance of extracting deeply meaningful experiences or instances to ensure that the sampling is not superficial or meaningless in the context of the overall analysis. In a similar manner, it may be construed that the self-reported perceptions of participants' deeper engagement were related to the need to identify meaningful portions of content and learning, as opposed to more superficial and unimportant facets. Mannion [32] suggests that any act of writing text can be deconstructed to identify the positions that the writer holds valid or important: by focusing on included text, participants may be able to identify missing content or learning that could provide a more holistic perspective.

Weblogs were also important in supporting students in charting and perceiving changes in their thinking. For example, Scott mentioned the ability of Weblogs to chart development of thoughts, which allowed him to understand how old and new knowledge became integrated. This finding is consistent with research on the utility of diary writing for distancing oneself from content and practice, and then for subsequently analyzing the content of the diary to identify patterns [see for example, 30]. Mannion [32] describes three phases of journal writing; in the first stage, before learning occurs, students tend to provide tentative, initial understanding of content. In the second stage, which is seen as a pause in the learning activity, journal writing allows students to reflect on what has been learned. In the third stage, students can connect reflections to other understanding. Comments by Cathy and Scott indicate that they perceived changes in their learning and development. In this context, Weblogs can be viewed as an artifact that mediates reflection and allows one to return to a specific experience [see for example, 23].

The second major theme in the positive experience of Weblogging was identified as the sense of community that developed from exposure to others' Weblogs. However, perceptions of community differed. Cathy's perception, for example, was more related to a sense of togetherness and belonging generated by the Weblogs. This conceptualization of community matches a definition offered by Unger and Wandersman [as cited in 33, p. 321], where community refers to "feelings of membership and belongingness." Scott's definition of community, on the other hand, referred to both an affective and a learning component. He perceived the Weblogs as reducing loneliness and increasing a sense of togetherness in striving for a common goal. While this affective component of community bears some similarity to the feelings expressed by Cathy, Scott also overtly referred to the concept of a "learning community" and the role of Weblogs in stimulating mutual growth. Rovai [33] identifies two components of a classroom community - connectedness and learning. A sense of connectedness accrues from one's perception of membership within a community, which is usually accompanied by feelings of belonging, acceptance, and the creation of relationships. Both Scott and Cathy referred to this aspect in their perception of community. Scott also referred to "struggling to understand this together." Paloff and Pratt [34] use the term "connectedness" in the sense indicated by Scott, where it connotes knowing through shared struggles with course material and the medium of learning. The learning component of the community was overtly mentioned by Scott and included the perception that knowledge and meaning construction are integral processes within the community, which is consistent with Paloff and Pratt's [34] conception of a learning community where members perceive a common learning goal and expectations. 
Current research on learning communities is often related to online and distance education contexts [see for example, 34], but a sense of community has been identified as important for fostering learning and a sense of belonging in face-to-face settings as well [35, 36]. A feeling of community may result not only in reduced feelings of isolation but also in increased motivation to learn [37]. In his research, Rovai [37] indicated that a higher sense of community was correlated with higher self-perceptions of learning, which to some extent matches Scott's perception of his learning. The other contribution of Weblogs to a sense of community was the ability to extend and generate conversations based on student comments. Participants perceived this extension to be valuable in furthering communication. Definitions of community are often closely tied to the level of interaction between participants [38], and Paloff and Pratt [34] suggest that evidence of student-student rather than instructor-student conversations are indicative of a learning community.

In summary, participants appreciated the ability of Weblogs to support their thinking and also appreciated the sense of community that emerged through the Weblogs. Participants used the Weblogs to spontaneously archive reflections, chart their progress, and reflect on their growth. In addition, reading others' reflections challenged individual thinking and contributed to a sense of closeness. However, Weblog usage also engendered some negative experiences that are described in the next section.

\section{NEGATIVE EXPERIENCES ABOUT WEBLOG USAGE}

Apart from the positive experiences, participants also expressed some hesitancy and negative feelings regarding Weblog usage. For many participants, this course provided the first opportunity to use Weblog technology and unfamiliarity with its usage led some participants to feel stressed. Participants were also concerned about the instructor's lack of guidance on format and frequency of Weblogging. Another negative perception about the use of Weblogs was participants' concern about their lack of content knowledge. In addition, because the Weblogs were open to public scrutiny, participants expressed concerns about safety of the environment.

\section{A. Uncertainty about Correct Usage of Weblogs}

For 7 of the 8 participants, the design course was the first opportunity to use Weblogs and they expressed uncertainty about correct usage of the technology. Tom, for example, felt that his lack of technological knowledge resulted in a feeling of stress, and since he was "new to it... so there was pressure of doing it right and correct." He also mentioned that unfamiliarity with the technology and the practice delayed and decelerated his Weblogging.

For three other participants, the novel technology combined with their lack of understanding about its usage to support learning resulted in engagement in the Weblogging activity purely for the purpose of meeting the class requirement: Thus, Weblogging became a somewhat stressful experience. Jack mentioned that the "external pressure" increased the difficulty of the task and interfered with his ability to post. He also felt that for some students the pressure resulted in their posting "something just to meet the assignment but not reflecting." He suggested that this attitude was especially true for those students who valued neither Weblogging nor reflection. Eric suggested that lack of time affected his Weblogging, since he was busy with other courses and it was thus "stressful to figure out something to write there." Tom, because of all the things he had to do, said that he "ended up making a response in despair."

Another concern was the unavailability of specific structure and guidance about Weblog usage and practice from the instructor. Participants' lack of prior experience with the technology led them to expect procedural and content guidelines for using the Weblogs. The lack of structure frustrated Betty who found 
it difficult to identify the important topics for reflection.

There was no definitive, "this is what you have to do, I want you to write about this topic or tell me your thoughts on this in particular." It was so open that when you have no limitations, it's hard to figure out what you write, what should be public knowledge, and what you keep private, and what the instructor feels is meaningful as compared to what is nonsense. It was hard because there were no guidelines. So it was frustrating in that sense.

Jane similarly felt that the lack of structure was disappointing and depleted her motivation and inspiration after a few weeks of trying to Weblog.

\section{B. Differences in Familiarity and Experience with Content}

Participants indicated that their prior content knowledge (or lack thereof) impacted their practice of and ability to engage in Weblogging. Participants who possessed more content-related experience were generally more active with Weblogging, while novice participants encountered difficulties in identifying areas for exploration or connecting information to their prior experiences. Eric mentioned that being a first semester student, he found it difficult to find something to write about since he "didn't have enough information or knowledge." In contrast, Betty had some prior teaching experience that she used to guide her writing and she mentioned its utility in helping her write on the Weblog: "I had a lot teaching experience and I would cite experiences. That really helped make sense of a lot of instructional design."

Differences in students' backgrounds posed difficulties for some participants because of their inability to connect with unfamiliar experiences or contexts expressed by other classmates; they found the content of such writing difficult to understand and apply to their own situation. Eric identified the Weblog as being personal and suggested that it might thus "be very difficult to evaluate by others." Because of the personal tone of Weblogs, Eric found it "difficult to give some idea, or to respond to others' thoughts or writing." Betty said that she perceived others' Weblogs to be at times frustrating and at other times helpful, depending on the writer.

And it's sometimes more frustrating to read other people's ideas when they are well beyond yours. And sometimes it helps because they might say something that clarifies for you. But they also may say something that makes you just more confused...the gentleman I worked with was military based, so all of his analogies were based on military. And I am not a military person. I don't necessarily understand military speak, so some of the things that he made correlations to I don't understand at all because it's not even in the realm of experience or understanding.

\section{Concerns about Privacy}

One participant, Scott, expressed doubts about the security of the environment because of its potential to be viewed by anyone with Internet access. Theoretically, anybody could respond to the writing on the Weblogs, and Scott was particularly afraid of attacks on his ideas without proper reasoning and factual backup.

Those who would offer "insights", I put that in quotes, that was not founded upon anything as you can tell is almost, in one sense, reaction of deeply held personal beliefs which are fine as long as they would have the opportunity to reflect upon themselves, inspired by research, not just something you think is right or wrong but why do you think is right or wrong. You disagree with 
me, that's fine, but tell me why. Just don't attach something and offer no reason as to your justification.

Scott was also concerned about the attention to be given to responses by unknown individuals, since he found it difficult to trust the sources, not knowing the background or expertise of the person.

... if you don't know the person via the Weblog... to the depth and credibility of their arguments or their thought, then I was skeptical and I was skeptical posting mine "cause somebody who had no, very limited knowledge would respond something then I don't know how much impact I should take that.

While Scott expressed a level of distrust of the environment that was not as apparent in other participants, the public nature of the Weblog caused some concern for other participants too. Participants were cautious about topic selection and chose not to write about anything personal, anything "too controversial" or too negative. Three participants expressed concerns about posting items related to the actions or opinions of peers. Lisa refrained from posting group or personal issues on the Weblog, and chose to keep a "professional orientation," eliminating personal issues and problems. Jane expanded on this concern and said she was "cautious" about posting a comment on any controversial issue.

\section{DISCUSSION ON NEGATIVE EXPERIENCES OF WEBLOG USAGE}

Participants expressed negative perceptions about Weblog usage for three main reasons: 1) the lack of explicit structure and guidance for blogging practice, 2) different levels of expertise with content and context, and, 3) concerns about privacy. Brockbank and McGill [24] note that engaging in reflective thinking requires provision of explicit space and time and provision of structured guidance on the format of reflective thinking and discourse. In this study, lack of guidance was associated with both procedure (i.e., how much to post and how often to post) and content (i.e., what specific content to address). In his research with pre-service teachers' journal writing, Garmon [10] identified that the imposition of a specific procedural requirement (twice a week with a minimum length requirement) was appreciated by some students but not by others. Some students felt that the guidelines were too restrictive, leading to journaling about unimportant issues. Similarly, students varied in their appreciation of the establishment of specific content foci: some students requested more freedom on topic selection, while others requested constrained topic starters to focus their writing. This disparity in opinions is similar to that expressed by participants in this study. While some participants mentioned that the lack of guidance was stressful, they were nevertheless able to Weblog successfully, while other students were unable to Weblog without a specific structure.

Korthagen [39] identifies this difference in student needs as a difference between internally oriented students who prefer to reflect using their own experiences and externally oriented students who prefer to be given guidelines and instructions. Korthagen also suggests that externally oriented students should be given safety and structure in the form of the instructions that they require. Jasper's [11] research indicated that two types of structure were important: one element of structure focused student attention on important aspects of their learning and the other element was the development of a structured writing format. In Jasper's study, students became more adept at engaging in reflection because they developed a practice of recording reflection and also because they were given explicit parameters focused on their learning. However, willingness to engage in reflection differs among individuals, and those who value reflection are more likely to engage in the process deeply [40]. 
The second hesitancy related to blogging was occasioned by different levels of context and content expertise. Contextual expertise in this case refers to the use of Weblogs and attendant technologies. Earlier research on the role of technological tools designed to support student learning has identified the importance of introducing students to the purpose and use of different types of tools [41, 42]. Thus, an introductory session might have induced students to blog more consistently regardless of prior experience with such technologies. Content expertise is more concerned with the integration of prior experiences as identified by participants. Those participants who were able to relate prior experiences to current content were more successful in blogging by drawing comparisons and engaging in more reflective thinking [43].

Concerns about privacy were also cited for lack of Weblog usage. Weblogs can be read by anyone with access to the Web. The wide access to private reflections and thoughts can be disturbing to some students [13] and specific attention must be paid to ethical and personal considerations of Weblogging. Weblogging shares much in common with student feelings about journaling. For example, Ballantyne and Packer's [9] research with doctoral students' journal writing indicated that students generally perceived journals as a safe space for expressing their ideas and feelings, but when they were exposed to an audience, they felt a need to be more circumspect in their writing. A similar perception was reported by participants in Spalding and Wilson's [44] research, where although participants appreciated others' feedback in broadening their views, they were still hesitant to share their private thoughts with others.

In summary, negative experiences related to Weblog usage were related to participant lack of knowledge and guidance about appropriate usage, lack of content knowledge, and concerns about privacy. Participants suggested that these experiences resulted in sporadic and inconsistent blogging.

\section{IMPLICATIONS FOR RESEARCH AND PRACTICE}

The initial themes that emerged through this exploratory study of students' experiences with Weblogs provide some important avenues for further research and practice. Weblogs are similar to paper-based journals in that writing is the singularly important expression of reflection. Also, Weblogs and journals offer a consistent space for individual reflection. As we noted in this study, however, students continue to encounter difficulties with consistently writing on Weblogs. Three primary research avenues are implied by the results of this study: (1) exploring methods to encourage student discourse with other peers in the instructional community and examining their effects on student reflection; (2) encouraging engagement in appropriate types of writing to aid learning and reflection; and, (3) identifying strategies to engage students more consistently in reflecting on the Weblogs.

Study participants indicated that they appreciated access to varied perspectives and one area of exploration should focus on different mechanisms for encouraging students to integrate various information sources into their writing, as well as to encourage them to publish comments to a wider audience. These sources may include peers within an instructional setting as well as members outside the immediate learning community. By expressly soliciting commentary and feedback from a wide audience, student reflections are likely to become more evaluative and critical [24]. Descriptive research of implementations that encourage Weblog interaction might help to identify appropriate strategies that encourage students to create thoughtful, critical reflections. Another valuable research avenue is the examination of the effects of others' commentary on the quality of student reflection. For example, how is quality of reflection affected by more or less commentary from others? Or, how is a student's own reflection affected by giving commentary to other peers? Privacy of thoughts emerged as a significant concern for some students and prevented very detailed posting of thoughts. This concern may impact student ability to receive and provide feedback as previously suggested. Instructors and designers may be able to mitigate this barrier by emphasizing the content-focused (and non-personal) nature of reflection. Research-based, practical strategies may also allow students to gain experience with providing 
constructive critical commentary, and perhaps alleviate any tendency to correlate feedback with personal attacks.

Research should also be directed at developing student ability to engage in writing. In this study, some participants mentioned writing for an audience, which connotes engagement in transactional writing [31]. Researchers and practitioners should identify how to encourage students to participate in both informational and transactional writing, thereby combining personal meaning-making with thoughtful expression in the form of discipline-sanctioned discourse. In addition, researchers may fruitfully investigate the impact of different writing types on the quality of reflection and learning.

Another area of exploration concerns the identification of specific mechanisms, strategies, and practices to encourage student reflection on the Weblogs. Earlier research indicates that students vary in their need for structure and guidance [10,39] for reflection. Some learners may be more likely to engage in and appreciate reflection $[39,40]$, while others might find reflection to be challenging or useless, as illustrated in this study and in a study by Garrmon [10]. Thus, research should focus on identifying the types of strategies that prove effective for encouraging reflection from different types of learners. For instructors and designers, the practical challenge is to identify an appropriate balance of structured and unstructured phases of reflection. One method might include supporting initial student logging with directed prompts and then gradually fading the support as the students gain competency and confidence in Weblogging and reflecting. Another option might be to design varied support mechanisms for reflection and allow students to individually choose an acceptable level of structure; however, the challenge is to encourage students to develop their own skills for engaging in structured reflection focused on their learning and interests. This study indicated that Weblogs allowed students to chart their learning progress. Building on this initial finding, it would be useful to identify additional aids to help students to further construct their learning and reflective activities. For example, a combination of Weblogs and concept mapping activities might allow students to map their learning in a more concrete fashion, thereby linking individual posts into a more holistic picture of content learning.

From a very practical perspective, study participants mentioned that lack of knowledge about Weblog technology negatively influenced their ability to reflect. Student use of tools and technologies tends to be circumscribed by instructor demonstrations [e.g., 45]; however, the lack of orientation on specific uses of technological tools and supports leads to unproductive use [46] and sporadic use as demonstrated in this study. Thus, it is important to include initial orientation sessions on the use and purpose of Weblogs to support consistent, appropriate use. An introductory session to basic practices and technology features can be supplemented by additional expert help as needed. In addition, descriptive user-centered research can identify additional technological features that may be effectively integrated in Weblogs to support students in their writing and reflection.

\section{DESIGN IMPLICATIONS}

Based on the findings from the reported study, we designed a subsequent study that was aimed at augmenting positive and mitigating negative experiences of Weblog usage. We also planned to collect data to examine effects of using Weblogs on student learning. Our new design tried to address the need for students to blog regularly on course content. Thus, we increased the amount of points allocated to blogging to $25 \%$ of the overall class grade. The assignment of grade points was in contrast to the previous study, where we assigned only $10 \%$ of the grade for Weblogging. We also designed a blog guide, a threepage description of why the blogs were important to the course and student learning, how to write blogs (technical description), and what they should contain. The blog guide was developed based on our findings in the reported study. 
For example, since Weblogs were perceived to positively affect thinking and learning through examination of content, we provided a list of questions to be addressed every week in the blogs, thereby ensuring that students could explore content systematically and deeply. We designed the questions to probe students' content understanding as well as their experiences of applying concepts to authentic situations, and our underlying goal was to encourage students to reflect on the questions and elaborate their thinking through blog posts. Another design option was based on our finding that Weblogs were perceived as being helpful in providing access to different viewpoints. Thus, we made it mandatory for students to integrate outside resources in their weekly writing, and we emphasized the need to integrate peer ideas and thoughts in their posts. The negative perceptions of Weblog usage, such as uncertainty about usage and concerns about privacy, were addressed primarily by providing a list of weekly questions and mandating weekly blog posting. Also, since the emphasis was on writing and reflection related to class content and learning, student concerns about privacy of personal expression was mitigated. Data sources for the second study included both interviews and blog artifacts, and while analysis is still ongoing, initial findings suggest that students found the blogging useful for charting learning and knowledge construction, and especially for creating learning artifacts that synthesized blog posts. Even students who entered the course with the initial assumption that the blogs would be unhelpful changed their views during the semester and commented on the utility of the blogs for charting their learning. Thus, proper design and implementation is paramount to successful use of Weblogs for learning.

The role of the instructor is important during implementation and design of any learning environment. Specifically, instructors who plan to implement Weblogs in their classrooms must address a few pedagogical and administrative questions in planning the use of this technology. Pedagogical questions deal with the utility and integration of Weblogs for student learning within the class context.

a. Have students been made aware of how Weblogging can help their thinking, reflection, and learning?

b. Do the Weblogs support writing and reflection that is integral to understanding the content?

c. Do the posts generated on the Weblogs form an integral component of the assessment or learning artifacts generated by the students?

d. Is there a requirement in place for students to blog at regular intervals?

e. Is sufficient assessment credit allotted for the Weblogging activity and posts?

f. Are trigger questions or some type of support mechanism provided for students to blog at regular intervals?

g. Are trigger questions directly linked to class content and learning artifacts?

h. Is there a requirement for students to read outside resources and blogs for integration within their own writing?

i. Are students directed to focus on content and learning as opposed to personal feelings?

j. Is there an emphasis on respectful, supportive, and critical commentary on the Weblogs?

Administrative questions to be addressed are about technical support for and maintenance of the Weblogs.

a. Is there an expert who can provide technical support and guidance to students as they use the Weblogs?

b. Is it more convenient to use a paid or free blogging server?

c. Is the blogging service easy and transparent to use? 
d. If additional media like audio (audioblogs) or video (videoblogs) are to be used, has sufficient server and bandwidth space been identified for use?

e. Has an orientation session been planned for informing students how to set up a blog and post items?

Using these questions as a guide, instructors who plan to use blogs for the first time within a classroom setting can do much to circumvent negative experiences and enhance the positive impacts of Weblog usage for student learning.

\section{CONCLUSION}

As a new and potentially powerful technology, the parameters and consequences of Weblog usage within higher education are still unexplored. Understanding graduate students' experiences of their Weblogging activities can impact the design and use of this technology in higher education settings. Especially, if Weblogs are to support specific types of thinking or collaborative practices in educational settings, student use and perceptions of the technology are important in informing practical and empirical educational implementations. We have presented some initial themes regarding the positive and negative experiences of students' Weblogging activities. This initial data supports the proposition that Weblogs can be used to support reflection individually; however, data also suggest that a more structured and guided introduction to the usage of this technology would be conducive to inculcating early and appropriate usage. Further research can explicate mechanisms and strategies by which Weblogs can be used to foster individual and group reflection and to create a sense of community, while avoiding situations that students might find threatening or disengaging.

\section{ABOUT THE AUTHORS}

Sharma Priya did her doctoral work at the University of Georgia and received her Ph.D. in Instructional Technology in 2001. In August 2001 she joined the Penn State faculty as assistant professor of instructional systems.

Ying Xie is an instructional designer in the Intructional Resource Center at George Mason University. She offers workshops about pedagogical use of technologies, designs prototypes, consults with faculty members, and conducts educational research. Her research focus has been the use of blogs in classrooms and creating cognitive tools for students learning. Her special interest lies in building constructivists' learning environments with new technologies. Ying Xie is a Ph.D. Candidate-ABD (All But Dissertation) in the Instructional Systems program at Penn State.

\section{REFERENCES}

1. Riley, D. "Blog numbers are closer to 34.5 million worldwide." The Blog Herald. January 10, 2005. http://www.blogherald.com/2005/01/10/blog-numbers-are-closer-to-345-million-wordwide/.

2. Oravec, J. A. Weblogs as an Emerging Genre in Higher Education. Journal of Computing in Higher Education 14: 21-44, Spr 2003.

3. Muukkonen, H. M. Lakkala \& K. Hakkarainen. Technology-Mediation and Tutoring: How Do They Shape Progressive Inquiry Discourse? Journal of the Learning Sciences 14: 527-565, 2005.

4. Wiltse, E. "Blog, Blog, Blog: Experiences with Web Logs in Journalism Classes."

Retrieved June 6, 2004 from 
http://banners.noticiasdot.com/termometro/boletines/docs/marcom/comunicacion/utexas/2004/utexas blogs.pdf.

5. Bartlett-Bragg, A. "Blogging to learn," The Knowledge Tree 4: December 2003. http://knowledgetree.flexiblelearning.net.au/edition04/pdf/Blogging to Learn.pdf.

6. Sade, G. "Weblogs as open constructive learning environments." Blogtalk Downunder. http://incsub.org/blogtalk/?page id=56.

7. Fiedler, S. \& P. Sharma. "Navigating personal information repositories with Weblog authoring and concept mapping." In S. O Tergan and T. Keller (Eds.), Knowledge and Information Visualization: Searching for Synergies, 302-325. Berlin: Springer-Verlag, 2005.

8. Boud, D., R. Keogh, \& D. Walker. Reflection: Turning Experience into Learning. London: Kogan Page, 1985.

9. Ballantyne, R. \& J. Packer. The Role of Student Journals in Facilitating Reflection at the Doctoral Level. Studies in Continuing Education 17(1-2): 29-45, 1995.

10. Garmon, M. A. The Benefits of Dialogue Journals: What Prospective Teachers Say. Teacher Education Quarterly 28(4): 37-50, Fall 2001.

11. Jasper, M. A. Nurses' Perceptions of the Value of Written Reflection. Nurse Education Today 19(6): 452-463, Aug 1999.

12. Fiedler, S. Personal Webpublishing as a reflective conversational tool for self-organized learning. In T. N. Burg (ed.), BlogTalks, 190-216. Wien, Austria, 2003.

13. Oravec, J. A. Bookmarking the World: Weblog Applications in Education. Journal of Adolescent \& Adult Literacy 45(7): 616-621, Apr 2002.

14. Paquet, S. Personal knowledge publishing and its uses in research. Knowledge Board. January 10, 2003. http://www.knowledgeboard.com/item/253/2010/5/2008.

15. Efimova L. \& A. de Moor. Beyond personal Webpublishing: An exploratory study of conversational blogging practices. 38th Annual Hawaii International Conference on System Sciences, Big Island, Hawaii, 2005.

16. Hernàndez-Ramos, $\mathbf{P}$. Web Logs and online discussions as tools to promote reflective practice. The Journal of Interactive Online Learning 3(1): Summer 2004.

17. Williams, J. B. \& J. Jacobs. Exploring the use of blogs as learning spaces in the higher education sector. Australasian Journal of Educational Technology 20(2): 232-247, Winter 2004.

18. Van Manen, M. Researching Lived Experience: Human Science for an Action Sensitive Pedagogy, 2nd ed. London, Ont.: Althouse Press, 1997.

19. Creswell, J. W. Qualitative Inquiry and Research Design: Choosing Among Five Traditions. Thousand Oaks, CA: Sage Publications, 1998.

20. Moustakas, C. E. Phenomenological Research Methods. Thousand Oaks, Calif.: Sage, 1994.

21. Rossman, G. B. \& S. F. Rallis. Learning in the Field: An Introduction to Qualitative Research. Thousand Oaks, Calif.: Sage Publications, 1998.

22. Salmon, G. Mirror, Mirror, On My Screen...Exploring Online Reflections. British Journal of Educational Technology 33(4): 379-391, Sep 2002.

23. Hoffman-Kipp, P., A. J. Artiles, \& L. Lopez-Torres. Beyond Reflection: Teacher Learning as Praxis. Theory into Practice 42(3): 248-254, Summer 2003.

24. Brockbank, A. \& I. McGill. Facilitating Reflective Learning in Higher Education. Suffolk: Great Britain: SRHE and Open University Press, 1998.

25. McPeck, J. Teaching Critical Thinking: Dialogue and Dialectic. New York: Routledge, 1990.

26. Yinger, R. Journal Writing as a Learning Tool. Volta Review 87(5): 21-33, Sep 1985.

27. Andrusyszyn, M. A. \& L. Davie. Facilitating Reflection through Interactive Journal Writing in an Online Graduate Course: A Qualitative Study. Journal of Distance Education 12(1): 103-126, 1997.

28. Hettich, P. Journal Writing: Old Fare or Nouvelle Cuisine? Teaching of Psychology 17(1): 36-39, February 1990.

29. Hershkowitz, R. \& B. B. Schwarz. Reflective Processes in a Mathematics Classroom with a Rich Learning Environment. Cognition and Instruction 17(1): 65-91, 1999. 
30. Sá, J. Diary Writing: An Interpretative Research Method of Teaching and Learning. Educational Research and Evaluation: An International Journal on Theory and Practice 8(2): 149-68, 2002.

31. Keys, C. W. Revitalizing instruction in scientific genres: connecting knowledge production with writing to learn in science. Science Education 83(2): 115-30, March 1999.

32. Mannion, G. Journal writing and learning: reading between the structural, holistic, and poststructural lines. Studies in Continuing Education 23(1): 94-115, May 2001.

33. Rovai, A. P. Development of an instrument to measure classroom community. Internet and Higher Education 5(3): 197-211, Autumn 2002.

34. Paloff, R. M. \& K. Pratt. Building Learning Communities in Cyberspace: Effective Strategies for the Online Classroom, 1st ed. San Francisco: Jossey-Bass, 1999.

35. Larson, B. E. Influences on social studies teachers' use of classroom discussion. Clearing House 73: 174-181, Jan-Feb 2000.

36. Tu, C. H. \& M. McIsaac. The relationship of social presence and interaction in online classes. American Journal of Distance Education 16(3): 131-150, 2002.

37. Rovai, A. P. Sense of community, perceived cognitive learning, and persistence in asynchronous learning networks. Internet and Higher Education 5(4): 319-332, 2002.

38. Harasim, L., S. R. Hiltz, L. Teles \& M. Turoff. Learning Networks: A Field Guide to Teaching and Learning Online. Cambridge, MA: MIT Press, 1995.

39. Korthagen, F. A. J. Linking reflection and technical competence: The logbook as an instrument in teacher education. European Journal of Teacher Education 22(2-3): 191-207, 1999.

40. Chi, M. T. H., N. de Leeuw, M. H. Chiu, and C. LaVancher. Eliciting self-explanations improves understanding. Cognitive Science 18(3): 439-477, 1994.

41. Saye, J. W. \& T. Brush. Scaffolding critical reasoning about history and social issues in multimediasupported learning environments. Educational Technology Research and Development 50(3): 77-96, September 2002.

42. Slotta, J. D. \& M. C. Linn. The knowledge integration environment: Helping students use the internet effectively. In M. J. Jacobson and R. B. Kozma (Eds.), Innovations in Science and Mathematics Education: Advanced Designs for Technologies of Learning, 193-226. Mahwah, NJ: Lawrence Erlbaum Associates, Inc., 2000.

43. Sharma, P. \& M. J. Hannafin. Scaffolding critical thinking in an online course: An exploratory study. Journal of Educational Computing Research 31(2): 181-208, 2004.

44. Spalding, E. \& A. Wilson. Demystifying reflection: A study of pedagogical strategies that encourage reflective journal writing. Teachers College Record 104(7): 1393-1421, Oct 2002.

45. Abbas, J. M. Smoothing the information seeking path: Removing representational obstacles in the middle school digital library environment. Denton, TX: University of North Texas, 2001.

46. Oliver, K. \& M. J. Hannafin. Student management of web-based hypermedia resources during open-ended problem solving. Journal of Educational Research 94: 75-92, 2000. 